Post-print of: International Journal of Refractory Metals and Hard Materials volume 33, July 2012, pages 38-43

\title{
Absence of the core-rim microstructure in TixTa1 - xCyN1 - y-based cermets developed from a pre-sintered carbonitride master alloy
}

\author{
E. Chicardi, J.M. Córdoba, M.J. Sayagués, F.J. Gotor
}

Instituto de Ciencia de Materiales de Sevilla (ICMS), CSIC-US, Américo Vespucio 49, 41092 Seville, Spain

\begin{abstract}
$(\mathrm{Ti}, \mathrm{Ta})(\mathrm{C}, \mathrm{N})$ solid solution-based cermets with cobalt as the binder phase were synthesised by a two-step milling process. The titanium-tantalum carbonitride solid solution (the ceramic phase) was obtained via a mechanically induced self-sustaining reaction (MSR) process from stoichiometric elemental $\mathrm{Ti}, \mathrm{Ta}$, and graphite powder blends in a nitrogen atmosphere. Elemental Co (the binder phase) was added to the ceramic phase, and the mixture was homogenised by mechanical milling (MM). The powdered cermet was then sintered in a tubular furnace at temperatures ranging from $1400{ }^{\circ} \mathrm{C}$ to $1600{ }^{\circ} \mathrm{C}$ in an inert atmosphere. The chemical composition and microstructure of the sintered cermets were characterised as ceramic particles grown via a coalescence process and embedded in a complex ( $\mathrm{Ti}, \mathrm{Ta})-\mathrm{Co}$ intermetallic matrix. The absence of the typical core-rim microstructure was confirmed.
\end{abstract}

\section{Keywords}

Ceramic-matrix composite; Titanium carbonitride; Mechanosynthesis; Microstructure; Cermets

\section{Introduction}

Cermets based on titanium carbonitride have attracted the attention of researchers due to their high hardness at high temperatures, thermal conductivity, chemical, thermal and wear resistances, and low friction coefficient to metals, among other properties [1], [2], [3], [4] and [5]. They have been successfully applied to new developments in the field of cutting tools and, compared with WC-Co hard metals, cermets improve the surface finish, ensuring excellent chip and tolerance control and dimensional accuracy of the workpieces [6], [7], [8] and [9].

However, cermets have poor toughness in comparison with cemented carbides [10], [11] and [12]. This lower toughness is often ascribed to the existence of the typical core/rim microstructure in the hard ceramic particles [13]. The core is generally composed of undissolved $\mathrm{Ti}(\mathrm{C}, \mathrm{N})$ particles existing in the original pre-sintered cermet. The rim phase, meanwhile, forms during the liquid-phase sintering when complex carbonitride solid solutions containing $\mathrm{Ti}$ and other transition metals precipitate from the oversaturated binder phase, 
which is made up of $\mathrm{Ni}, \mathrm{Co}$, or an alloy of these metals, onto the undissolved core particles [14], [15], [16] and [17]. The interface formed between the core and rim can generate residual stresses that favour crack propagation and, consequently, can deteriorate the toughness of the material [18].

Although the core-rim interface can be detrimental to some properties of cermets, it has been amply demonstrated that the mechanical behaviour of the rim phase is also responsible for improving the overall properties of these materials [14], [19], [20] and [21]. Therefore, if it were possible to remove the core phase in favour of the rim phase, the final properties of cermets could be further enhanced, especially the fracture resistance or toughness. To achieve this goal, some authors have proposed the use of complex transition metal carbonitrides (master alloys) as the ceramic raw material in the manufacture of cermets [22], [23] and [24]. Moreover, by modifying the chemical composition of the complex carbonitride phase, the final mechanical properties of cermets may be modulated [2] and [24].

Mechanically induced self-sustaining reactions (MSR) have been used as a reproducible manufacturing process to obtain complex transition metal carbonitrides [25], [26] and [27]. This reactive milling method takes advantage of the strong exothermic character of the carbide and nitride formation from the elements to promote self-propagating reactions during milling and obtain complex carbonitrides with high purity and good stoichiometric control. It has also been reported that this methodology may be successfully applied to the development of cermets with the basic $\mathrm{Ti}(\mathrm{C}, \mathrm{N})-\mathrm{Ni} / \mathrm{Co}$ composition [28] and [29]. In a previous study [30], the development of $(\mathrm{Ti}, \mathrm{Ta})(\mathrm{C}, \mathrm{N})$ cermets was successfully achieved because of the application of the MSR technology. During the MSR process, an intermetallic binder phase is formed, which induced the formation of an unusual inverse core-rim microstructure after sintering.

The aim of the present work was to develop cermets without the typical core-rim microstructure using a pre-made complex $(\mathrm{Ti}, \mathrm{Ta})(\mathrm{C}, \mathrm{N})$ carbonitride as the ceramic raw material (master alloy). The chemical composition and microstructure of both the powdered and sintered cermets obtained by this new methodology are here characterised.

\section{Experimental}

Titanium powder (99\% in purity, < 325 mesh, Strem Chemicals), tantalum powder $(99.6 \%$ in purity, $<325$ mesh, Alfa-Aesar), graphite powder (<270 mesh, Fe $\leq 0.4 \%$, Merck), and cobalt powder (99.8\% in purity, $<100$ mesh, Strem Chemicals) were used in this work.

First, $46.5 \mathrm{~g}$ of an elemental $\mathrm{Ti}, \mathrm{Ta}$, and graphite powder mixture with an atomic $\mathrm{Ti}: \mathrm{Ta}: \mathrm{C}$ ratio of 0.8:0.2:0.5 was placed together with 13 tempered steel balls $(\mathrm{d}=20 \mathrm{~mm}, \mathrm{~m}=32.6 \mathrm{~g})$, which corresponds to a powder-to-ball mass ratio (PBR) of $~ 1 / 9.3$, in a $300 \mathrm{ml}$ tempered steel vial (67HRC). The mixture was ball milled under 6 atm of high-purity nitrogen gas ( $\mathrm{H} 2 \mathrm{O}$ and $\mathrm{O} 2 \leq 3$ $\mathrm{ppm}$, Air Liquide) at a spinning rate of $400 \mathrm{rpm}$, for both the rotation of the supporting disc and the superimposed rotation in the direction opposite to the vial, using a modified planetary ball mill (Vario-Planetary Mill PULVERISETTE 4, Fritsch) to obtain by a MSR process a ( $\mathrm{Ti}, \mathrm{Ta})(\mathrm{C}$, $\mathrm{N})$ carbonitride solid solution with a Ti0.8Ta0.2C0.5N0.5 nominal composition. The planetary mill allowed operation at a constant gas pressure and the detection of self-propagating 
reactions during milling [25]. After detecting ignition, milling was prolonged for $5 \mathrm{~min}$ to ensure full conversion [31].

Subsequently, $6 \mathrm{~g}$ of a mixture composed of $80 \mathrm{wt} . \%$ of the $(\mathrm{Ti}, \mathrm{Ta})(\mathrm{C}, \mathrm{N})$ ceramic phase obtained by the MSR process and $20 \mathrm{wt} . \%$ of Co was introduced together with 7 tempered steel balls $(\mathrm{d}=15 \mathrm{~mm}, \mathrm{~m}=13.7 \mathrm{~g}), \mathrm{PBR}$ of $~ 1 / 16$, in a $45 \mathrm{ml}$ tempered steel vial (67HRC) and ball milled under $6 \mathrm{~atm}$ of high-purity helium gas $(\mathrm{H} 2 \mathrm{O}<3 \mathrm{ppm}, \mathrm{O} 2<2 \mathrm{ppm}$ and $\mathrm{CnHm}<0.5$ $\mathrm{ppm}$, Air Liquide) at a spinning rate of $600 \mathrm{rpm}$ using a modified planetary ball mill (Planetary Micro Mill PULVERISETTE 7, Fritsch) also allowing operation at a constant gas pressure. The mixture was milled for $30 \mathrm{~min}$, which was the minimum time necessary to produce the optimal homogenisation of the powdered cermets under our experimental milling conditions, as required to achieve an optimal densification after sintering [28].

The powdered cermets were then compacted by uniaxial pressing at $15 \mathrm{MPa}$ for $5 \mathrm{~min}$ and cold isostatic pressing at $200 \mathrm{MPa}$ for $10 \mathrm{~min}$ to yield cylinders of $13 \mathrm{~mm}$ in diameter and $9 \mathrm{~mm}$ in height. Finally, the green compacts were sintered at different temperatures from $1400{ }^{\circ} \mathrm{C}$ to $1600{ }^{\circ} \mathrm{C}$ for $60 \mathrm{~min}$ (heating and cooling rates of $5{ }^{\circ} \mathrm{C} / \mathrm{min}$ ) under a flowing inert atmosphere (Argon gas, $\mathrm{H} 2 \mathrm{O} \leq 8 \mathrm{ppm}$ and $\mathrm{O} 2 \leq 2 \mathrm{ppm}$, Linde) in a horizontal tubular furnace (AGNI Type IGM1360 model no. RTH-180-50-1H, AGNI). The density of the sintered cermets was measured in accordance with the Archimedes method and the total porosity by image analysis using IMAGE PRO PLUS software.

X-ray diffraction diagrams of powders and polished surfaces of cermets were obtained with a Panalytical X'Pert Pro instrument that had been equipped with a $\theta / \theta$ goniometer using $\mathrm{Cu} K \alpha$ radiation $(40 \mathrm{kV}, 40 \mathrm{~mA})$, a secondary $\mathrm{K} \beta$ filter, and an $\mathrm{X}^{\prime}$ Celerator detector. The diffraction patterns were scanned from $20^{\circ}$ to $140^{\circ}(2 \theta)$ in a step-scan mode at a step of $0.02^{\circ}$ and a counting time of $275 \mathrm{~s} / \mathrm{step}$. Silicon powder (Standard Reference Material 640c, NIST) was used for calibration of the diffraction line positions. The space group symmetry and the lattice parameters of the phases were calculated from the whole set of peaks of the XRD diagram by using the FULLPROF Suite free software containing DICVOL, WinPLOTR and FullProf computer programmes [32].

Scanning electron microscopy (SEM) images were obtained on a Hitachi S-4800 SEM-FEG microscope. Transmission electron microscopy (TEM) images and electron diffraction (ED) patterns were taken on a $200 \mathrm{kV}$ Philips CM200 microscope equipped with a SuperTwin objective lens and a LaB6 filament (point resolution $\varnothing=0.25 \mathrm{~nm}$ ). Powder samples were dispersed in ethanol, and droplets of the suspension were deposited onto a holey $\mathrm{C}$ film copper grid. For the TEM characterisation of consolidated cermets, thin discs ( $3 \mathrm{~mm} \emptyset$ ) were prepared by a process of subsequent cutting, polishing, dimpling, and ion milling (DuoMiller, Gatan Inc. and ion miller model no. 1010, Fischione). The transition metal content in the ceramic and binder phases was measured by energy dispersive X-ray spectrometry (EDX) with detectors coupled in both the SEM and TEM. The carbon and nitrogen content in the ceramic phase was determined by electron energy loss spectroscopy (EELS) with a Gatan model 766-2K parallel detection electron spectrometer in the TEM. The EELS spectra were recorded in a diffraction mode with a collection angle of $1.45 \mathrm{mrad}$. The measured energy resolution at the zero-loss peak of the coupled microscope/spectrometer system was approximately $2 \mathrm{eV}$. A 
low-loss spectrum was also recorded with each edge in the same illuminated area. After background subtraction with a standard power law function, the spectra were deconvoluted for plural scattering with the Fourier-ratio method, and semi-quantitative analyses were then conducted. All of these treatments were performed using the EL/P programme (Gatan).

\section{Results and discussion}

The titanium, tantalum, and graphite powder mixture milled under a nitrogen atmosphere in the PULVERISETTE 4 mill showed a highly exothermic self-sustaining reaction (an MSR process) after $37 \mathrm{~min}$. Five minutes later, milling was stopped. After mixing the resulting sample from this first treatment with 20 wt.\% of elemental Co for $30 \mathrm{~min}$ in the PULVERISETTE 7 mill, the final product was checked by XRD (Fig. 1a). The XRD diagram showed the reflection lines corresponding to $\mathrm{Co}$ and a cubic phase with an $\mathrm{Fm}-3 \mathrm{~m}$ space group. In accordance with the reference diffraction patterns of titanium and tantalum carbides and nitrides, i.e., TiC (321383), TaC (35-0801), TiN (38-1420), and TaN (49-1283), this cubic phase, which was formed during the MSR process, was assigned to a complex titanium-tantalum carbonitride with the general formula TixTa1 - xCyN1 - y. Moreover, a minor amount of unreacted tantalum was also detected.

The $\mathrm{Ta} / \mathrm{Ti}$ and $\mathrm{C} / \mathrm{N}$ ratios in the TixTa1 - xCyN1 - y ceramic phase were determined from multiple EDX-SEM and EELS-TEM measurements, respectively. Representative EDX and EELS spectra are shown in Fig. 2. A Ta/Ti ratio of 0.15 , lower than the 0.25 starting nominal ratio, was found in accordance with the presence of minor unreacted Ta in the sample. Contrarily, the EELS spectra (Fig. 2b) confirmed the presence of nitrogen in the ceramic phase and the formation of a carbonitride phase. A C/N ratio of 1.78 was observed, which was higher than the composition expected from the initial elemental mixture, and again, it was attributed to the presence of the unreacted Ta. The values obtained from EDX and EELS quantification allowed us to propose an average composition of the ceramic phase of Ti0.87Ta0.13C0.64N0.36, which is the average of the measurements made in 30 different ceramic particles.

Powdered cermets composed of the complex titanium-tantalum carbonitride as the only ceramic phase and $\mathrm{Co}$ as the binder phase were pressureless sintered at temperatures between $1400{ }^{\circ} \mathrm{C}$ and $1600{ }^{\circ} \mathrm{C}$. XRD diagrams of the sintered cermets are shown in Fig. $1(\mathrm{~b}-\mathrm{g})$, where the reflection lines are assigned to two different phases corresponding to the ceramic and binder components of the cermets. As expected, the reflections of the ceramic phase matched with a TixTa1 - xCyN1 - y composition. However, the binder phase detected in the XRD diagrams was not an elemental $\mathrm{Co}$, but an intermetallic compound containing $\mathrm{Ti}$, $\mathrm{Ta}$, and Co, as confirmed by EDX analysis. It is clear that the intermetallic phase was formed during the liquid-phase sintering by dissolving part of the main ceramic phase and the unreacted Ta phase present in the powdered cermet into the elemental Co.

The intermetallic phase was assigned to a cubic ( $\mathrm{Ti}, \mathrm{Ta}) \mathrm{Co} 2$ solid solution by comparison with the reference diffraction patterns of cubic-TiCo2 (17-0031) and cubic-TaCo2 (38-0736). In Fig. 3 , the XRD diagrams in the $44^{\circ}-47.5^{\circ} 2 \theta$ range are shown. This was ascertained by indexing the XRD lines of the binder phase with DICVOL06 software that confirmed a cubic structure with an $\mathrm{Fd}-3 \mathrm{~m}$ space group. The formation, during the sintering process, of this cubic ( $\mathrm{Ti}, \mathrm{Ta}) \mathrm{Co} 2$ 
solid solution was corroborated by ED, as illustrated in Fig. 4. This depiction shows representative EDPs taken along the [101] and [112] zone axes in the binder area of the cermet sintered at $1575{ }^{\circ} \mathrm{C}$. EDX-TEM measurements in these same areas confirmed the 1:2 stoichiometry of the intermetallic phase, which can then be described as TixTa1 - xCo2 (Fig. $5 a)$. The cubic carbonitride ceramic phase with an $\mathrm{Fm}-3 \mathrm{~m}$ space group was also corroborated by ED in this sample, and in Fig. 4, representative EDPs taken along the [001] and [101] zone axes are shown. The presence of tantalum and titanium in the ceramic particles was confirmed by EDX-TEM measurements (Fig. 5b).

Notably, in Fig. 1, the position of the XRD lines for the TixTa1 - xCyN1 - y ceramic phase is unchanged for cermets sintered at increasing temperatures, and most importantly, appears at exactly the same $2 \theta$ position in the powdered cermet. The TixTa1 - xCo2 lines shifted to higher $2 \theta$ values when the temperature was increased from $1400{ }^{\circ} \mathrm{C}$ to $1550^{\circ} \mathrm{C}$, suggesting a slight change in chemical composition (Fig. 3). Determination of the lattice parameter for both ceramic and binder phases supported these features (Table 1). The lattice parameter of the TixTa1 - xCyN1 - y hard phase remained practically invariant for different temperatures, and moreover, when compared with the powdered cermet (4.316 $\AA$ ). This confirms a constant ceramic composition during the sintering process. However, the lattice parameter of the cubic TixTa1 - xCo2 binder phase decreased with the sintering temperature until $1550{ }^{\circ} \mathrm{C}$. From this temperature, the lattice parameter reached a constant value, suggesting stability in the binder phase composition.

A careful EDX-SEM semiquantitative analysis was performed in all the cermets to verify the composition of ceramic and binder phases with temperature (30 different measurements for each phase and temperature) and to confirm the general trend issued by the XRD study. The TixTa1 - xCyN1 - y ceramic phase showed a constant Ta/Ti ratio of 0.15 (less than the nominal value of 0.25 and identical to that of the powdered cermet) irrespective of the sintering temperature and in accordance with the XRD results. In contrast, the binder phase possessed a higher $\mathrm{Ta} / \mathrm{Ti}$ ratio of 0.7 on average. This high Ta content was a consequence of the presence of unreacted $\mathrm{Ta}$ in the powdered cermets that were incorporated into the binder phase during sintering. As the sintering temperature was raised, a slight Ti enrichment was observed as a result of the partial dissolution of TixTa1 - xCyN1 - y ceramic particles in the binder. Moreover, the $\mathrm{Co} /(\mathrm{Ta}+\mathrm{Ti})$ ratio measured in the binder phase showed the 1:2 stoichiometry found previously for the TixTa1 - xCo2 intermetallic solid solution.

The density and total porosity of cermets sintered at increasing temperatures is also shown in Table 1. The gradual decrease in the porosity of cermets with increasing sintering temperature, as can be observed in Fig. 6, resulted in an improved density. A maximum density and a minimum porosity were obtained at $1575{ }^{\circ} \mathrm{C}$, which can be regarded as the optimum pressureless sintering temperature. Above this temperature, the density was not further enhanced. A loss of density in the specimen sintered at $1600{ }^{\circ} \mathrm{C}$ was due to a loss by gravity of the molten binder phase because of an excessive fluidisation during the sintering process [30].

The high temperatures required for achieving full densification of cermets is attributed to the presence of Ta in the binder phase due to its high melting point $\left(3017^{\circ} \mathrm{C}\right)$ when compared with titanium $\left(1668{ }^{\circ} \mathrm{C}\right)$ and cobalt $\left(1495^{\circ} \mathrm{C}\right)$. In a previous work dealing with cermets without 
tantalum as an additive, the sintering was possible at $1400^{\circ} \mathrm{C}$ by applying the same procedure as in the present work [28].

SEM characterisation (Fig. 6) of the cermets showed that the ceramic particles did not possess the characteristic core-rim microstructure, confirming that this can be achieved by the use of pre-sintered complex carbonitrides (master alloys). Cermets sintered at the lower temperatures showed the presence of ceramic particles with an irregular morphology as a result of their partial dissolution in the liquid binder and their preferential growth through a coalescence phenomenon. At higher sintering temperatures, the enhanced coalescence growth led to the formation of large faceted particles of $\sim 5 \mu \mathrm{m}$ with binder trapped inside. The binder phase inside the hard particles can be also observed in Fig. 4. The ceramic particles dissolved in the binder during sintering, with reprecipitation not being noticeable, were probably due to insufficient binder saturation. Moreover, it is possible that particles that have grown sufficiently by coalescence were not favoured for further growth by reprecipitation. The smaller ceramic particles $(\sim 1 \mu \mathrm{m})$ seen in the micrographs can be considered part of the original particles. The final microstructure of the cermet sintered at the optimal temperature was therefore characterised as having ceramic particles with a bimodal size distribution.

The absence of the core-rim can be seen more clearly when comparing the microstructure of cermets obtained in this study with the literature [12] or with those developed in a previous work [30], where it appeared as an inverse core-rim microstructure (Fig. 7). The presence of the binder phase inside big faceted particles suggesting that they have grown from small ones by a coalescence process can be observed in Fig. 7b (this work). However, large particles observed in Fig. 7a (previous work [30]) with a core-rim structure do not show the binder phase inside them, which put forward a growth characterised by a dissolution/re-precipitation process during sintering. Fig. 7 also shows that the coalescence growth leads to larger particles than the dissolution/re-precipitation process. In Fig. 7b, some large faceted particles showed the existence of small areas with different contrasts that could correspond to the coalescence of particles with slightly different stoichiometries. However, these differences in composition, if any, should be minor because EDX measurements did not allow for differentiation. However, EDPs performed in particles exhibiting this characteristic contrast (Fig. 4) revealed a unique structural orientation and, therefore, can be considered as monocrystalline

\section{Conclusions}

The use of a synthesised titanium-tantalum carbonitride solid solution (TixTa1 - xCyN1 - y) by a MSR process, instead of a mixture of different ceramic phases, as the only raw ceramic material to fabricate cermets using $\mathrm{Co}$ as the binder phase allowed the fabrication of cermets without the characteristic core-rim microstructure. The pressureless sintering process did not alter the chemical composition of the TixTa1 - xCyN1 - y ceramic phase. However, the resulting binder phase was a TixTa1 - xCO2 intermetallic solid solution instead of the initial elemental cobalt. The intermetallic phase formed during sintering through the dissolution of part of the ceramic component in the Co melt and then crystallised during the cooling step. 
The microstructure of the cermets was characterised as ceramic particles grew via a coalescence process and without the typical core-rim microstructure. The coalescence of the ceramic particles induced the trapping of the binder phase inside them. Large faceted particles that were grown by coalescence of smaller ones possessed a single crystal structure.

\section{Acknowledgements}

This work was supported by the Spanish Government under grant no. MAT2010-17046, which was financed in part by the European Regional Development Fund of 2007-2013. E. Chicardi and J. M. Córdoba were supported by the CSIC through JAE-Pre and JAE-Doc grants, respectively, which are financed in part by the European Social Fund (ESF). 


\section{References}

[1] L. Backerud, B. Carlsson, R. Oskarsson, M. Mikus

Study of the nickel-rich and cobalt-rich corners of the systems Ni-Ti-C and Co-Ti-C

Scand J Metall, 3 (1974), pp. 225-235

[2] P. Ettmayer, H. Kolaska, W. Lengauer, K. Dreyer

$\mathrm{Ti}(\mathrm{C}, \mathrm{N})$ cermets - metallurgy and properties

Int J Refract Metals Hard Mater, 13 (1995), p. 343

[3] E. Gustenau-Michalek, P. Herzig, A. Neckel

Titanium carbonitrides, Ti(C, N): electronic structure and chemical bonding

J Alloys Compd, 219 (1995), pp. 303-306

[4] H. Pastor

Titanium-carbonitride-based hard alloys for cutting tools

Mater Sci Eng, 105-106 (1988), pp. 401-409

[5] S. Zhang

Material development of titanium carbonitride-based cermets for machining application (1998), pp. 521-543

[6] S. Cardinal, A. Malchère, V. Garnier, G. Fantozzi

Microstructure and mechanical properties of TiC-TiN based cermets for tools application Int J Refract Metals Hard Mater, 27 (2009), pp. 521-527

[7] R.J. Czura

Cermets tackle tough jobs

Mod Mach Shop, 62 (1989), pp. 66-74

[8] H. Kolaska

Cermets. Cutting materials with a future

Wire, 40 (1990), pp. 343-346

[9] C. Wick

Cermet cutting tools 
Manuf Eng, 99 (1987), pp. 35-40

[10] S.G. Huang, L. Li, O. Van der Biest, J. Vleugels

Influence of WC addition on the microstructure and mechanical properties of $\mathrm{NbC}-\mathrm{Co}$ cermets

J Alloys Compd, 430 (2007), pp. 158-164

[11] X. Zhang, N. Liu, C. Rong

Microstructure and fracture toughness of TiC-ZrC-WC-Mo-Ni cermets

Int J Refract Metals Hard Mater, 26 (2008), pp. 346-356

[12] A.J. Sherman, G. Smith, D. Baker, R. Toth

Cermet tool and die materials from metal coated powders

M. Singh, T. Jessen (Eds.), 25th Annual Conference on Composites, Advanced Ceramics, Materials, and Structures: A, Amer Ceramic Soc, Westerville (2001), pp. 95-102

[13] S.-Y. Ahn, S.-W. Kim, S. Kang

Microstructure of Ti(CN)-WC-NbC-Ni cermets

J Am Ceram Soc, 84 (2001), pp. 843-849

[14] S.Y. Ahn, S. Kang

Formation of core/rim structures in Ti(C, N)-WC-Ni cermets via a dissolution and precipitation process

J Am Ceram Soc, 83 (2000), pp. 1489-1494

[15] H.-O. Andrén

Microstructure development during sintering and heat-treatment of cemented carbides and cermets

Mater Chem Phys, 67 (2001), pp. 209-213

[16] E. Rudy

Constitution of ternary titanium-tungsten-carbon alloys

J Less Common Met, 33 (1973), pp. 245-273

[17] P. Wally, M. Ueki, P. Ettmayer

Stability of the two-phase structure of the hard particles in $\mathrm{Ti}(\mathrm{C}, \mathrm{N})$ base cermets and diffusional phenomena in $\mathrm{Ti}(\mathrm{C}, \mathrm{N})-(\mathrm{Ti}, \mathrm{Mo}) \mathrm{C}$ diffusion couples

Funtai Oyobi Fummatsu Yakin, 43 (1996), pp. 520-525 
[18] Y. Liu, Y.Z. Jin, H.J. Yu, J.W. Ye

Ultrafine $(\mathrm{Ti}, \mathrm{M})(\mathrm{C}, \mathrm{N})$-based cermets with optimal mechanical properties

Int J Refract Metals Hard Mater, 29 (2011), pp. 104-107

[19] D. Mari, S. Bolognini, G. Feusier, T. Cutard, T. Viatte, W. Benoit

TiMoCN based cermets Part II. Microstructure and room temperature mechanical properties

Int J Refract Metals Hard Mater, 21 (2003), pp. 47-53

[20] S. Mun, S. Kang

Effect of $\mathrm{HfC}$ addition on microstructure of $\mathrm{Ti}(\mathrm{CN})-\mathrm{Ni}$ cermet system

Powder Metall, 42 (1999), pp. 251-256

[21] F. Qi, S. Kang

A study on microstructural changes in $\mathrm{Ti}(\mathrm{CN})-\mathrm{NbC}-\mathrm{Ni}$ cermets

Mater Sci Eng A, 251 (1998), pp. 276-285

[22] W. Jing, W. Yisan, D. Yichao

Production of $(\mathrm{Ti}, \mathrm{V}) \mathrm{C}$ reinforced Fe matrix composites

Mater Sci Eng A, 454-455 (2007), pp. 75-79

[23] Y.K. Kim, J.-H. Shim, Y.W. Cho, H.-S. Yang, J.-K. Park

Mechanochemical synthesis of nanocomposite powder for ultrafine ( $\mathrm{Ti}, \mathrm{Mo}) \mathrm{C}-\mathrm{Ni}$ cermet without core-rim structure

Int J Refract Metals Hard Mater, 22 (2004), pp. 193-196

[24] E. Rudy

Spinodal carbonitride alloys for tool and wear applications. United States

[25] J.M. Córdoba, M.A. Avilés, M.J. Sayagués, M.D. Alcalá, F.J. Gotor

Synthesis of complex carbonitride powders TiyMT1 - yCxN1 - x (MT: Zr, V, Ta, Hf) via a mechanically induced self-sustaining reaction

J Alloys Compd, 482 (2009), pp. 349-355

[26] J.M. Córdoba, M.J. Sayagués, M.D. Alcalá, F.J. Gotor

Monophasic TiyNb1 - YCxN1 - x nanopowders obtained at room temperature by MSR 
J Mater Chem, 17 (2007), pp. 650-653

[27] J.M. Córdoba, M.J. Sayagués, M.D. Alcalá, F.J. Gotor

Monophasic nanostructured powders of niobium, tantalum, and hafnium carbonitrides synthesized by a mechanically induced self-propagating reaction

J Am Ceram Soc, 90 (2007), pp. 381-387

[28] J.M. Córdoba, M.D. Alcalá, M.A. Avilés, M.J. Sayagués, F.J. Gotor

New production of TiCxN1 - x-based cermets by one step mechanically induced self-sustaining reaction: Powder synthesis and pressureless sintering

J Eur Ceram Soc, 28 (2008), pp. 2085-2098

[29] A. Gallardo-López, A. Morales-Rodríguez, A. Domínguez-Rodríguez, J.M. Córdoba, M.A. Avilés, F.J. Gotor

High temperature mechanical properties of $\mathrm{Ti}(\mathrm{C}, \mathrm{N})-\mathrm{Co}-\mathrm{Mo} 2 \mathrm{C}$ cermets

(2010), pp. 83-88

[30] E. Chicardi, J.M. Cordoba, M.J. Sayagues, F.J. Gotor

Inverse core-rim microstructure in $(\mathrm{Ti}, \mathrm{Ta})(\mathrm{C}, \mathrm{N})$-based cermets developed by a mechanically induced self-sustaining reaction

Int J Refract Metals Hard Mater, 31 (2011), pp. 39-46

[31] L. Takacs

Self-sustaining reactions induced by ball milling

Prog Mater Sci, 47 (2002), pp. 355-414

[32] J. Rodriguez-Carvajal

FULLPROF

(2010) 


\section{Figure captions}

Figure 1. X-ray powder diffraction diagrams of powdered cermet (a) and cermets sintered at different temperatures: (b) $1400{ }^{\circ} \mathrm{C}$, (c) $1450{ }^{\circ} \mathrm{C}$, (d) $1500{ }^{\circ} \mathrm{C}$, (e) $1550{ }^{\circ} \mathrm{C}$, (f) $1575{ }^{\circ} \mathrm{C}$, and (g) $1600{ }^{\circ} \mathrm{C}$. (•) TixTa1 - xCyN1 - y; ( ) cubic (TixTa1 - x)Co2; (•) cobalt; (O) tantalum.

Figure 2. Representative EDX-SEM and EELS-TEM spectra corresponding to the TixTa1 - xCyN1 - y ceramic phase.

Figure 3. X-ray powder diffraction diagrams of sintered cermets in the $44^{\circ}-47.5^{\circ} 2 \theta$ region, where the [311] and [222] reflections of the intermetallic phase appear. ( ) Cubic (TixTa1 $\mathrm{x}) \mathrm{CO} 2$.

Figure 4. Bright-field TEM image and ED patterns along the [101] and [112] corresponding to the cubic TixTa1 - xCo2 binder phase; and along the [001] and [101] corresponding to the cubic TixTa1 - xCyN1 - y ceramic phase in cermet sintered at $1575^{\circ} \mathrm{C}$.

Figure 5. Representative EDX-TEM measurements for the (a) binder and (b) ceramic phases shown in Fig. 4. Iron observed in the binder was due to milling media contamination and Co in the ceramic phase to trapped binder inside the particles.

Figure 6. Representative SEM micrographs, by secondary electron mode, of cermets sintered at $1400{ }^{\circ} \mathrm{C}, 1500{ }^{\circ} \mathrm{C}$ and $1575^{\circ} \mathrm{C}$.

Figure 7. SEM micrographs of TixTa1 - xCyN1 - y-based cermets (a) showing a core-rim microstructure developed during sintering by a dissolution/re-precipitation process [30], and (b) showing a microstructure without core-rim characterised by a coalescence growth. 
Table 1. Lattice parameters of ceramic and binder cubic phases, absolute density and total porosity of cermets sintered at increasing temperatures.

\begin{tabular}{|l|l||l|l|l||}
\hline $\begin{array}{l}\text { Sintering } \\
\text { temperature }\left({ }^{\circ} \mathbf{C}\right)\end{array}$ & $\begin{array}{l}\text { Ceramic } \\
\text { phase }(\AA)\end{array}$ & $\begin{array}{l}\text { Intermetallic } \\
\text { phase }(\AA)\end{array}$ & $\begin{array}{l}\text { Absolute } \\
\text { density } \\
\left(\mathbf{g} / \mathbf{c m}^{\mathbf{3}}\right)\end{array}$ & $\begin{array}{l}\text { Total } \\
\text { porosity } \\
(\mathbf{\%})\end{array}$ \\
\hline 1400 & 4.3155 & 6.739 & 6.71 & 4.5 \\
\hline 1450 & 4.3149 & 6.730 & 6.85 & 3.9 \\
\hline 1500 & 4.3149 & 6.720 & 7.14 & 2.4 \\
\hline 1550 & 4.3153 & 6.710 & 7.22 & 1.6 \\
\hline 1575 & 4.3150 & 6.712 & 7.32 & 0.8 \\
\hline 1600 & 4.3149 & 6.713 & 7.27 & 2.0 \\
\hline
\end{tabular}


Figure 1

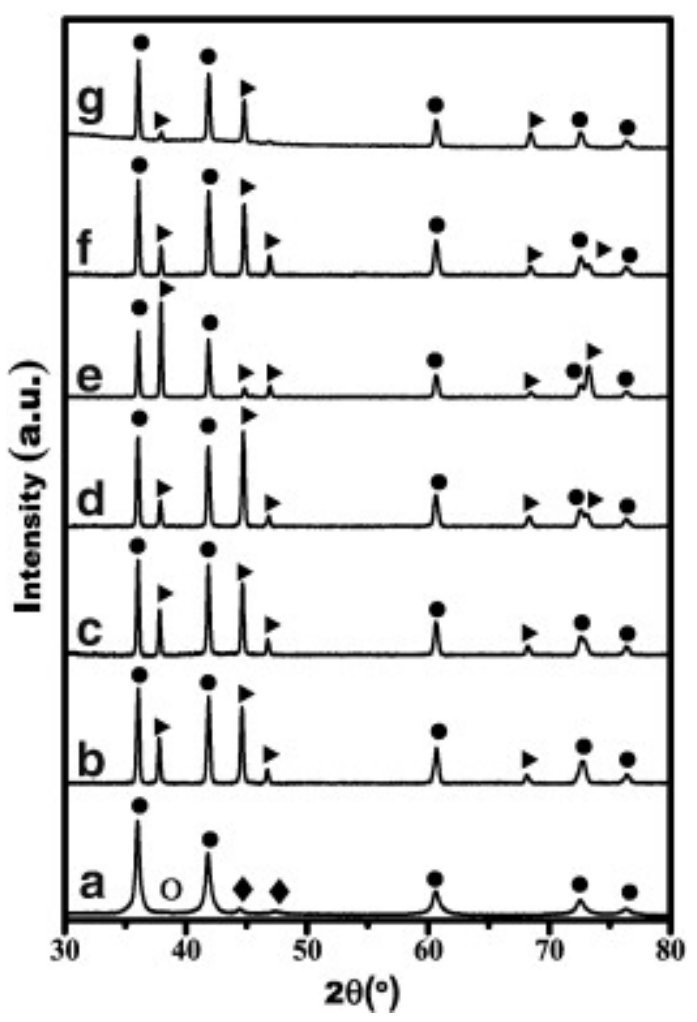


Figure 2
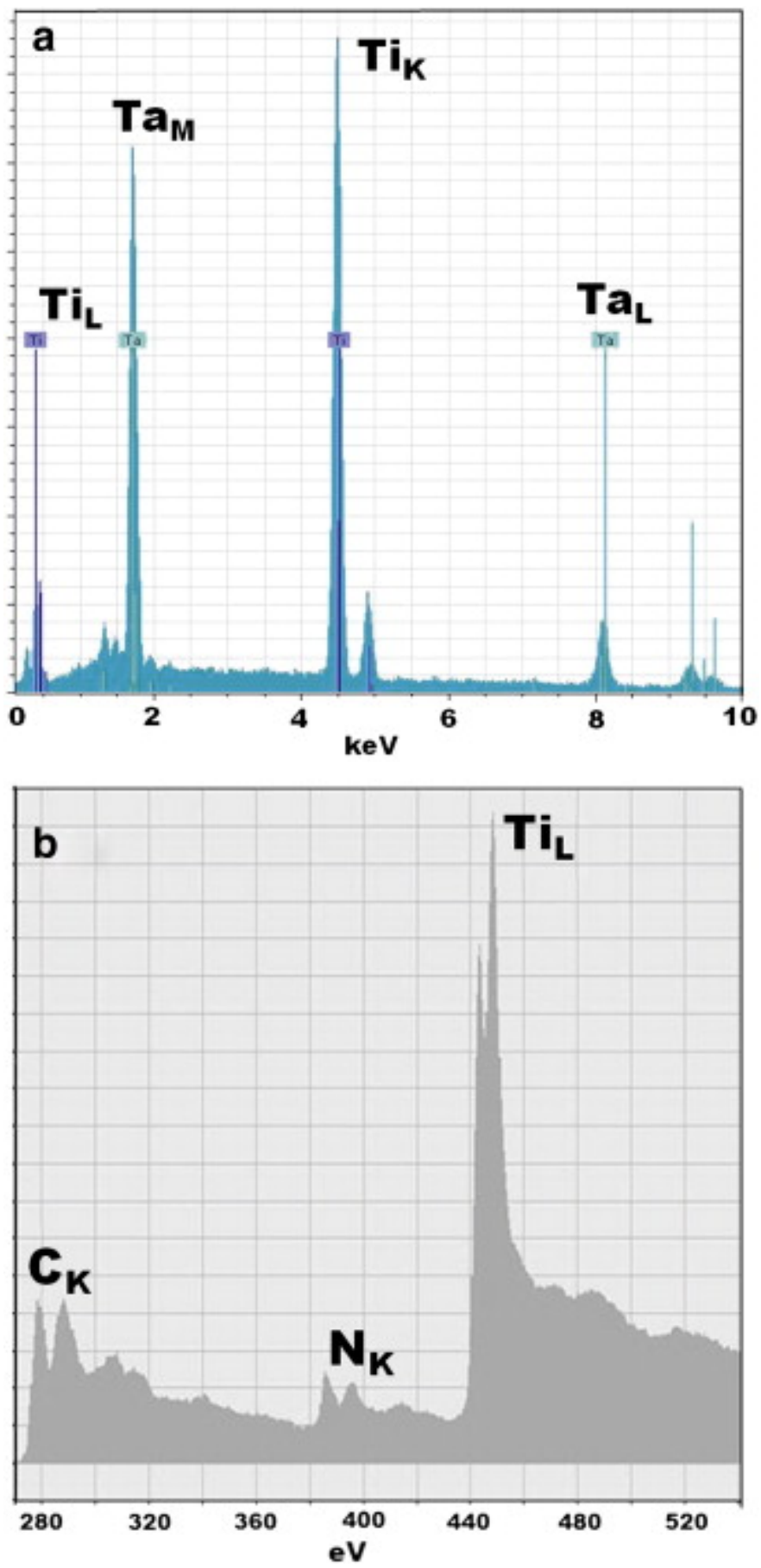
Figure 3

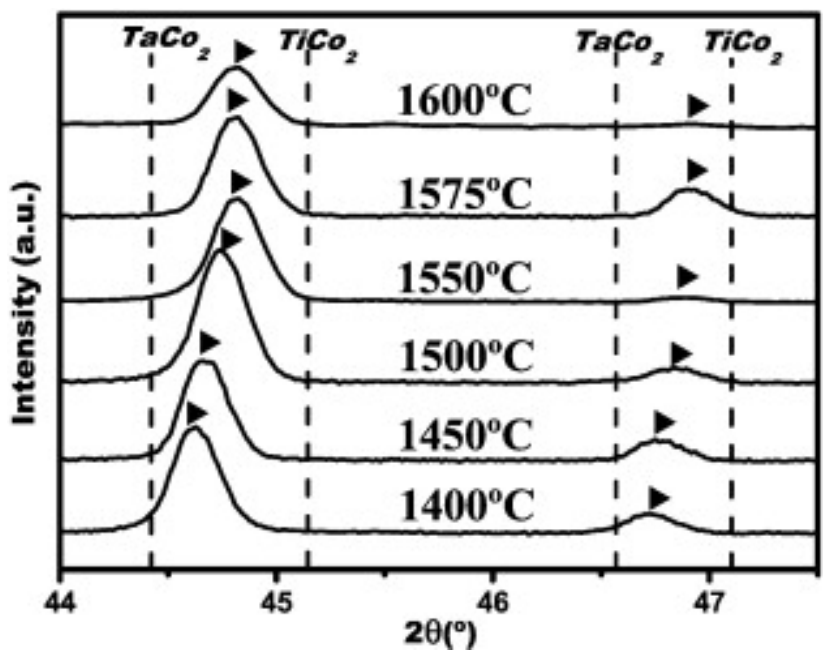


Figure 4

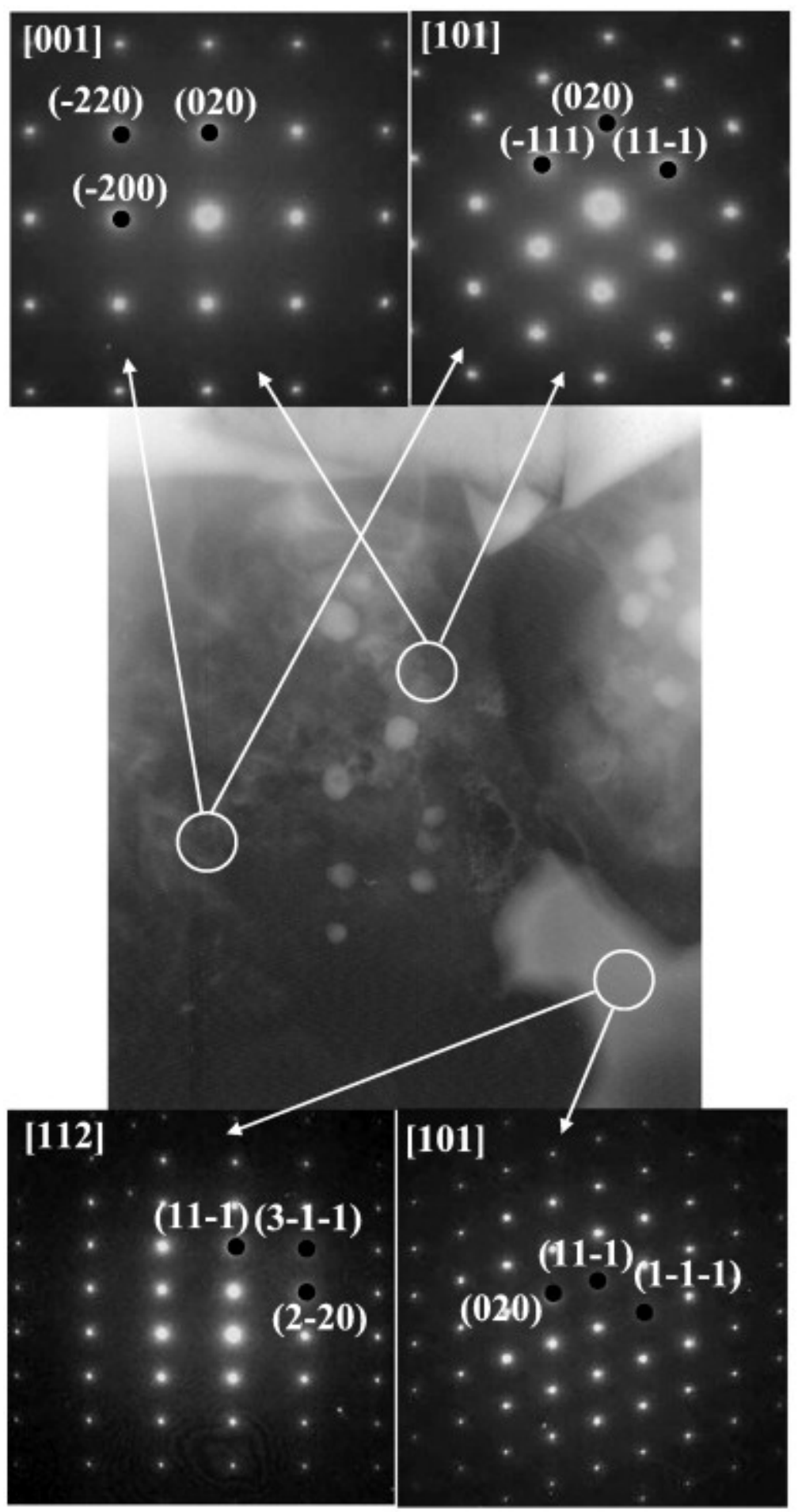


Figure 5
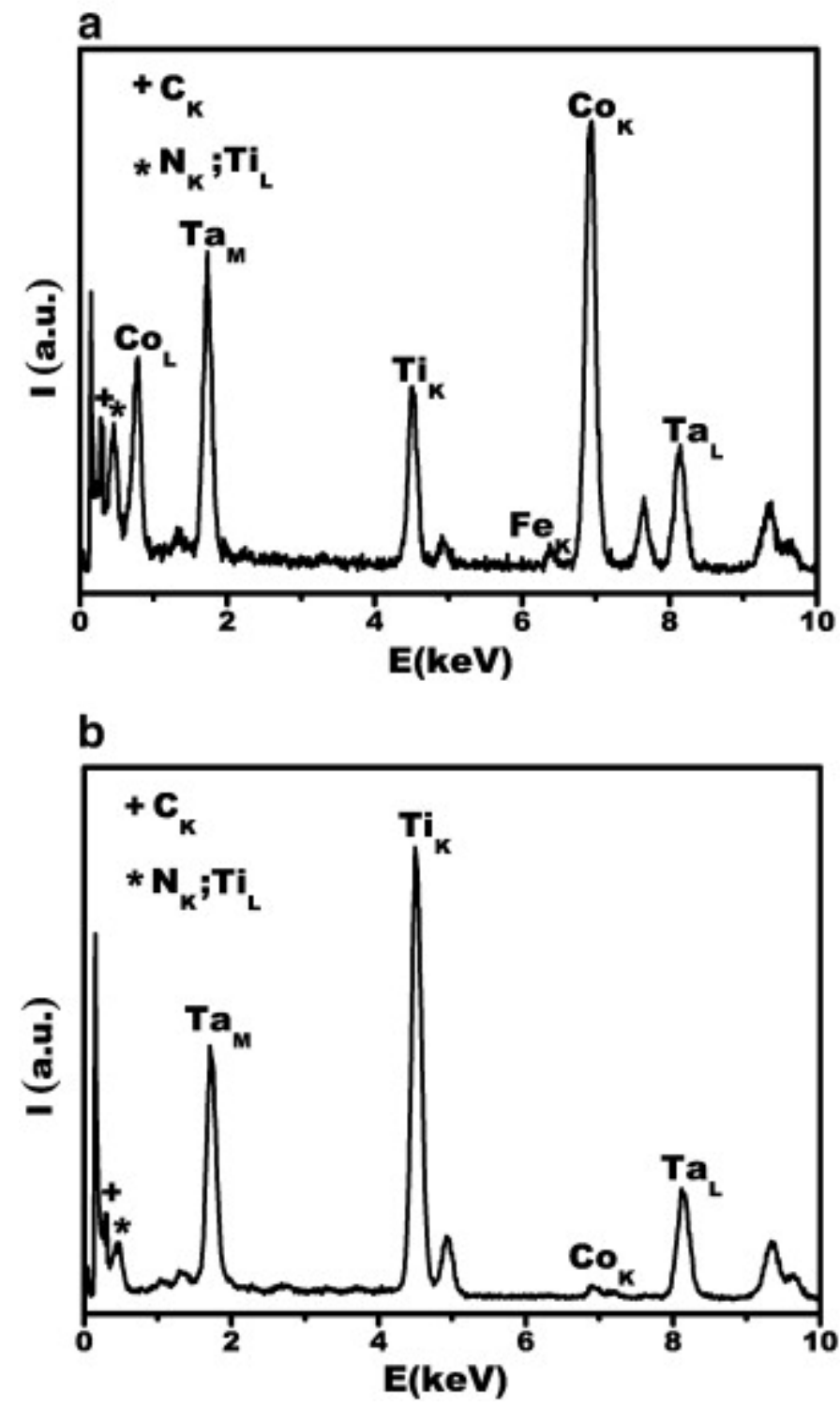
Figure 6
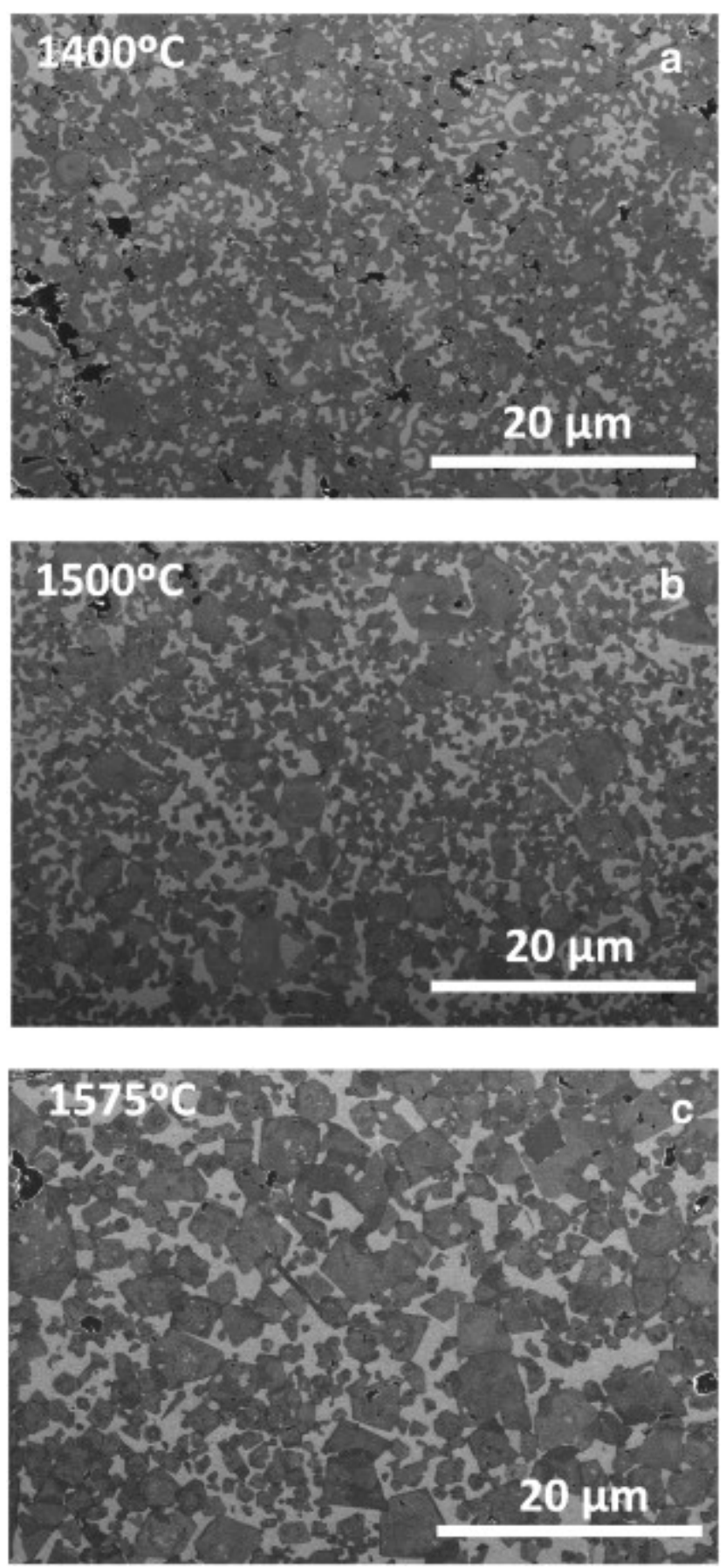
Figure 7
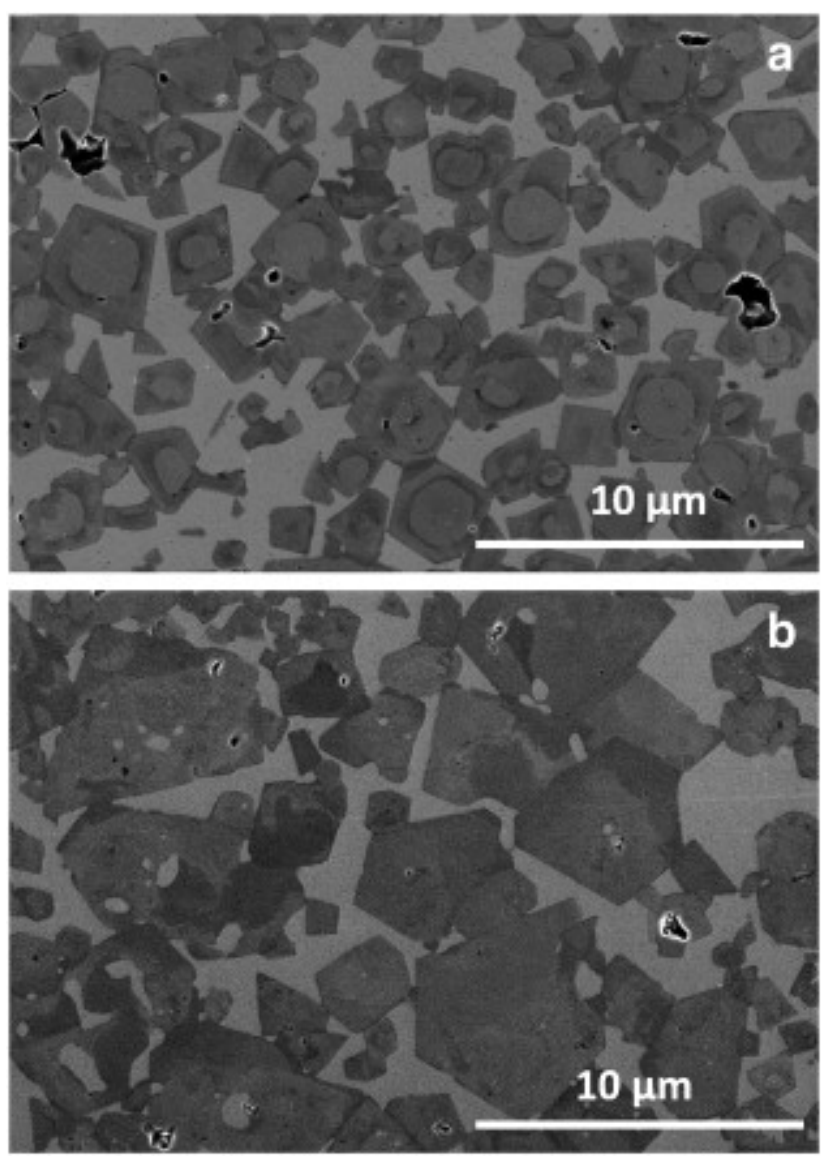